\title{
Activity Levels and Exercise Motivation in Patients With COPD and Their Resident Loved Ones
}

Citation for published version (APA):

Mesquita, R., Nakken, N., Janssen, D. J. A., van den Bogaart, E. H. A., Delbressine, J. M. L., Essers, J. M. N., Meijer, K., van Vliet, M., de Vries, G. J., Muris, J. W. M., Pitta, F., Wouters, E. F. M., \& Spruit, M. A. (2017). Activity Levels and Exercise Motivation in Patients With COPD and Their Resident Loved Ones. Chest, 151(5), 1028-1038. https://doi.org/10.1016/j.chest.2016.12.021

Document status and date:

Published: 01/05/2017

DOI:

10.1016/j.chest.2016.12.021

Document Version:

Publisher's PDF, also known as Version of record

Document license:

Taverne

Please check the document version of this publication:

- A submitted manuscript is the version of the article upon submission and before peer-review. There can be important differences between the submitted version and the official published version of record.

People interested in the research are advised to contact the author for the final version of the publication, or visit the DOI to the publisher's website.

- The final author version and the galley proof are versions of the publication after peer review.

- The final published version features the final layout of the paper including the volume, issue and page numbers.

Link to publication

\footnotetext{
General rights rights.

- You may freely distribute the URL identifying the publication in the public portal. please follow below link for the End User Agreement:

www.umlib.nl/taverne-license

Take down policy

If you believe that this document breaches copyright please contact us at:

repository@maastrichtuniversity.nl

providing details and we will investigate your claim.
}

Copyright and moral rights for the publications made accessible in the public portal are retained by the authors and/or other copyright owners and it is a condition of accessing publications that users recognise and abide by the legal requirements associated with these

- Users may download and print one copy of any publication from the public portal for the purpose of private study or research.

- You may not further distribute the material or use it for any profit-making activity or commercial gain

If the publication is distributed under the terms of Article $25 \mathrm{fa}$ of the Dutch Copyright Act, indicated by the "Taverne" license above, 


\title{
Activity Levels and Exercise Motivation in Patients With COPD and Their Resident Loved Ones
}

\author{
Rafael Mesquita, MSc, PT; Nienke Nakken, MSc; Daisy J. A. Janssen, MD, PhD; Esther H. A. van den Bogaart, MSc; \\ Jeannet M. L. Delbressine, BSc; Johannes M. N. Essers, MSc; Kenneth Meijer, PhD; Monique van Vliet, MD; \\ Geeuwke J. de Vries, MD, PhD; Jean W. M. Muris, MD, PhD; Fabio Pitta, PhD, PT; Emiel F. M. Wouters, MD, PhD; \\ and Martijn A. Spruit, PhD, PT
}

BACKGROUND: Resident loved ones of patients with COPD can play an important role in helping these patients engage in physical activity. We aimed to compare activity levels and exercise motivation between patients with COPD and their resident loved ones; to compare the same outcome measures in patients after stratification for the physical activity level of the loved ones; and to predict the likelihood of being physically active in patients with a physically active resident loved one.

METHODS: One hundred twenty-five patient/loved one dyads were cross-sectionally and simultaneously assessed. Sedentary behavior, light activities, and moderate to vigorous physical activity (MVPA) were measured with a triaxial accelerometer during free-living conditions for at least 5 days. Five exercise-motivation constructs were investigated: amotivation, external regulation, introjected regulation, identified regulation, and intrinsic regulation.

RESULTS: Patients spent more time in sedentary behavior and less time in physical activity than their loved ones $(P<.0001)$. More intrinsic regulation was observed in loved ones compared with patients $(P=.003)$, with no differences in other constructs. Despite similar exercise motivation, patients with an active loved one spent more time in MVPA (mean $31 \mathrm{~min} / \mathrm{d}$; 95\% CI, 24-38 min/d vs mean, $18 \mathrm{~min} / \mathrm{d}$; 95\% CI, $14-22 \mathrm{~min} / \mathrm{d} ; P=.002$ ) and had a higher likelihood of being active (OR, 4.36; 95\% CI, 1.41-13.30; $P=.01$ ) than did patients with an inactive loved one after controlling for age, BMI, and degree of airflow limitation.

CONCLUSIONS: Patients with COPD are more physically inactive and sedentary than their loved ones, despite relatively similar exercise motivation. Nevertheless, patients with an active loved one are more active themselves and have a higher likelihood of being active.

TRIAL REGISTRY: Dutch Trial Register (NTR3941).

CHEST 2017; 151(5):1028-1038

KEY WORDS: COPD; family caregivers; outcome assessment; physical activity; sedentary lifestyle

ABBREVIATIONS: BREQ-2 = Behavioral Regulation and Exercise Questionnaire 2; GOLD = Global Initiative for Chronic Obstructive Lung Disease; METs = metabolic equivalents of task; MVPA = moderate to vigorous physical activity

AFFILIATIONS: From the Department of Research and Education (Drs Janssen, Wouters, and Spruit; Mr Mesquita; and Mss Nakken, van den Bogaart, and Delbressine) CIRO, Horn, the Netherlands; the Department of Respiratory Medicine (Dr Wouters and Mr Mesquita), Maastricht University Medical Centre+, Maastricht, the Netherlands; the Department of Human Movement Science (Dr Meijer and $\mathrm{Mr}$
Essers), Faculty of Health, Medicine and Life Sciences; and the Caphri School of Public Health and Primary Care (Dr Muris), Department of Family Medicine, Maastricht University, Maastricht, the Netherlands; the Department of Respiratory Medicine (Dr van Vliet), Zuyderland, Heerlen, the Netherlands; and the Department of Respiratory Medicine (Dr de Vries), Zuyderland, Sittard-Geleen, the Netherlands; and the Laboratory of Research in Respiratory Physiotherapy (Dr Pitta), Department of Physiotherapy, State University of Londrina (UEL), Londrina, Brazil. 
COPD is characterized by breathlessness and fatigue that leads to problems with multiple activities of daily living. ${ }^{1}$ Therefore, patients with COPD are less physically active ${ }^{2}$ and spend more time in sedentary behavior $^{3}$ compared with healthy subjects. This physically inactive/sedentary lifestyle can at least in part contribute to the development of extrapulmonary features and comorbidities. ${ }^{4}$

Adopting a healthier lifestyle, including less sedentarism and more leisure-time physical activity, is one of the main goals of integrated COPD management. ${ }^{5,6}$ Nevertheless, it seems difficult for patients to change their physical activity levels following structured pulmonary rehabilitation programs (with or without individual physical activity counseling sessions) $)^{7,8}$ or using pedometer-based counseling programs. ${ }^{9}$

Family members/resident loved ones may play an important role in achieving this goal, ${ }^{10}$ for instance by encouraging patients with COPD to go on joint daily walks or to engage more in household activities. To consider family-based lifestyle interventions for patients with COPD and their resident family members, we first need a better understanding of the physical activity, sedentary behaviors, and exercise motivation of the patient's family members. Indeed, $92 \%$ of the resident loved ones of patients with COPD have one or more chronic conditions themselves (eg, persistent airflow obstruction, obesity, and symptoms of anxiety/ depression), ${ }^{11}$ which may all affect their daily physical activity levels.

To the best of our knowledge, no previous study has specifically addressed physical activity levels, sedentary behavior, and exercise motivation of loved ones of patients with COPD. Therefore, the aim of this study was threefold: (1) to compare physical activity, sedentary behavior, and exercise motivation between patients with COPD and their resident loved ones; (2) to compare physical activity, sedentary behavior, and exercise motivation in patients after stratification for the physical activity level of their resident loved ones; and (3) to predict the likelihood of being physically active in patients with physically active resident loved ones. A priori, we hypothesized that patients are more physically inactive and sedentary than their resident loved ones and that patients with COPD with a physically active resident loved one have a higher likelihood of being physically active themselves.

\section{Methods}

\section{Study Design and Participants}

This is a cross-sectional analysis using baseline data from the Home Sweet Home study, an observational longitudinal study on the home environment of patients with COPD. ${ }^{12}$ The Home Sweet Home study was approved by the Medical Ethics Committees United, the Netherlands (NL42721.060.12/M12-1280). Recruitment of participants was performed during hospital admission or at the outpatient respiratory clinic in four hospitals throughout the southeastern part of the Netherlands. Patients with COPD who participated in the COPD, Health status and Comorbidities (CHANCE) study ${ }^{13}$ and met the inclusion criteria of the Home Sweet Home study were also asked to participate in the study. Patients and resident loved ones who were included in the Home Sweet Home study were conveniently used in

FUNDING/SUPPORT: Data used in the current analyses are part of the Home Sweet Home study, which was funded by the Lung Foundation Netherlands, Leusden, the Netherlands [Grant 3.4.12.024], and by a research grant from Boehringer-Ingelheim Netherlands, the Netherlands.

This work was presented at the American Thoracic Society 2015 International Conference, May 15-20, 2015, Denver, CO and appeared in Am J Respir Crit Care Med. 191;2015:A2005.

CORRESPONDENCE TO: Rafael Mesquita, MSc, PT, Department of Research and Education, CIRO, Hornerheide 1, 6085 NM, Horn, the Netherlands; e-mail: rafaelmesquita14@ymail.com

Copyright (c) 2017 American College of Chest Physicians. Published by Elsevier Inc. All rights reserved.

DOI: http://dx.doi.org/10.1016/j.chest.2016.12.021 the current analysis. Therefore, the sample size calculation was based on the primary aims of that study. ${ }^{12}$ Patients were included in the current analysis if they met the following criteria: Global Initiative for Chronic Obstructive Lung Disease (GOLD) COPD diagnosis with a moderate to very severe degree of airflow limitation (GOLD grades 2$4)^{5}$; no exacerbation or hospitalization within the previous 4 weeks; presence of a resident loved one (ie, a person living with a COPD patient, regardless of whether or not he or she provides informal care to the patient); and results of a valid physical activity assessment (see next section). Patients recruited during hospital admission were assessed only when in stable condition (ie, no exacerbation or hospitalization within the previous 4 weeks). Patients or loved ones, or both, were excluded in case of cognitive impairment or an inability to speak or understand Dutch. All participants provided written informed consent. The inclusion period took place between July 2013 and December 2014.

\section{Assessments}

All assessments were performed during home visits. Assessments were composed of demographics, clinical data, body composition (body impedance analysis), postbronchodilator lung function (spirometry), functional mobility (Timed Up \& Go test ${ }^{14,15}$ ), exercise motivation (Behavioral Regulation and Exercise Questionnaire $2^{16}$ ), generic and COPD-specific health status (EuroQol-5 Dimensions ${ }^{17}$ and COPD Assessment Test, ${ }^{18}$ respectively), care dependency (Care Dependency Scale ${ }^{19}$ ), and symptoms of anxiety and depression (Hospital Anxiety and Depression Scale ${ }^{20}$ ) (further details can be found in e-Appendix 1, Assessments). At the end of the home visit, patients and their loved ones received an activity monitor for the assessment of physical activity and sedentary behavior. 
These outcomes were assessed during free-living conditions with the MOX Activity Monitor (Maastricht Instruments BV), a triaxial accelerometer validated in patients with COPD and in healthy subjects. ${ }^{21,22}$ Patients and their loved ones wore their own monitors concomitantly, and the accelerometer data of each patient/loved one dyad were synchronized. Participants had the device attached to the front of the right thigh and were instructed to keep it there for at least 7 days. A valid activity-level assessment was defined as at least 5 days of assessment (three weekdays + Saturday + Sunday), ${ }^{23}$ each with at least $10 \mathrm{~h}$ of measurement. Data assessed during waking hours from the average value of all valid days were used to calculate each outcome measure: time in sedentary behavior $(<1.5$ metabolic equivalents of task [METs]), time in light activities (1.5-3.0 METs), and time in moderate to vigorous physical activity (MVPA, $>3.0 \mathrm{METs}$ ). Participants were considered physically active if they spent $\geq 30 \mathrm{~min}$ in MVPA at least 5 days per week. ${ }^{24}$ Moreover, the time in weight-bearing, non-weight bearing, and dynamic activities, as well as the characteristics of 10-min bouts of activity in MVPA were estimated. Daily hourly patterns were also analyzed (ie, a graphic representation of the intensity of activity in counts/min during the course of a day), as was daily television-viewing time based on self-reporting.

Exercise motivation was assessed with the Behavioral Regulation and Exercise Questionnaire 2 (BREQ-2). ${ }^{16}$ This instrument focuses on the reasons underlying people's decisions to engage or not in exercise, based on principles of the self-determination theory. ${ }^{16}$ The
BREQ-2 is composed of 19 items distributed in five subscales: amotivation (eg, "I don't see why I should have to exercise"), external regulation (eg, "I exercise because other people say I should"), introjected regulation (eg, "I feel guilty when I don't exercise"), identified regulation (eg, "It's important to me to exercise regularly"), and intrinsic regulation (eg, "I exercise because it is fun"). ${ }^{16}$ These are different forms of regulation that lie along a continuum ranging from completely non-self-determined to completely self-determined regulation. ${ }^{16}$ Scores per subscale are provided and can range from 0.00 (not true for the participant) to 4.00 (very true for the participant).

\section{Statistical Analyses}

Continuous variables were tested for normality with the Shapiro-Wilk test, presented as mean $\pm \mathrm{SD}$ or median (interquartile range [IQR]), and compared with unpaired $t$ tests or Mann-Whitney $U$ tests, as appropriate. Categorical variables were presented as absolute and relative frequencies and were compared using the $\chi^{2}$ test or Fisher's exact test. Analyses after controlling for age, BMI, and degree of airflow limitation were performed with an analysis of covariance, and the results were presented as mean and 95\% CI. Logistic regression models were generated to predict the likelihood (OR and 95\% CI) of being physically active for patients with physically active resident loved ones. Statistical analyses were performed using IBM SPSS Statistics, version 22.0 (SPSS, Inc.) or GraphPad Prism 6 (GraphPad Software), and a $P$ value $<.05$ was considered significant.

\section{Results}

Of the 194 patient/loved one dyads who completed the baseline assessment of the Home Sweet Home study, 69 dyads could not be included in the current analysis due to an invalid activity level assessment. Patients and loved ones from these dyads are referred to as nonincluded. e-Figure 1 summarizes the reasons for ineligibility, and e-Table 1 presents the comparison between included and nonincluded participants. Nonincluded patients were slightly younger, more often required care from relatives, and had worse lung function and worse health status than included patients. Nonincluded loved ones used less medication and had slightly better functional mobility and more anxiety symptoms than included loved ones. Details on participants screened for eligibility and willingness to participate in the Home Sweet Home study have been described elsewhere. ${ }^{11,12}$

\section{General Characteristics}

Overall, patients with COPD were characterized by a moderate to severe degree of airflow limitation and impaired health status (Table 1). About one-fourth of the patients referred had a walking aid (rollator or cane) or used long-term oxygen therapy. Compared with their loved ones, patients more often received informal care from relatives; had a higher burden of comorbidities; used more medication; had a lower BMI and fat-free mass index, worse lung function, functional mobility, and health status, and more symptoms of depression; and were more care dependent (Table 1). Ten patients (8\%) and one loved one $(1 \%)$ reported current participation in pulmonary rehabilitation.

\section{Physical Activity and Sedentary Behavior}

Both patients and loved ones had a median of 6 (IQR, 6-6) valid days of activity monitoring. The total number of valid days in each group was 737 days, 487 of which (66\%) were weekdays. Patients spent more time in sedentary behavior and non-weight bearing activities than did loved ones, whereas loved ones spent more time in light activities, MVPA, and weight bearing and dynamic activities than did patients (Table 2). The amount of time spent in $\geq 10$-min bouts of MVPA was similar between groups, as was the frequency and duration of these bouts. These results were observed irrespective of the day of the week (e-Table 2). More loved ones than patients were considered physically active, that is, $\geq 30 \mathrm{~min}$ in MVPA on $\geq 5$ days (30\% vs $17 \% ; P=.01)$. Daily hourly patterns revealed that resident loved ones performed their activities at higher intensities compared with patients, despite a similar activity pattern (Fig 1). The amount of selfreported time spent watching television was similar between groups (Table 2). 
TABLE 1 ] General Characteristics of the Groups

\begin{tabular}{|c|c|c|c|}
\hline Characteristics & $\begin{array}{l}\text { Patients With COPD } \\
\qquad(\mathrm{n}=125)\end{array}$ & $\begin{array}{l}\text { Resident Loved Ones } \\
\qquad(\mathrm{n}=125)\end{array}$ & $P$ Value \\
\hline Male sex, No. (\%) & $69(55)$ & $54(43)$ & .06 \\
\hline Age, y & $67(62-74)$ & $66(61-73)$ & .48 \\
\hline $\begin{array}{l}\text { Relationship between patient and } \\
\text { loved one }\end{array}$ & & & .48 \\
\hline Partners (married or not), No. (\%) & $122(97)$ & $123(98)$ & \\
\hline Son/daughter of patient, No. (\%) & $2(2)$ & $2(2)$ & \\
\hline Friends, No. (\%) & $1(1)$ & $0(0)$ & \\
\hline Working situation & & & .32 \\
\hline Paid job, No. (\%) & $13(10)$ & $23(18)$ & \\
\hline Retired, No. (\%) & $63(51)$ & $52(42)$ & \\
\hline Household work, No. (\%) & $18(14)$ & $29(23)$ & \\
\hline Unable to work, No. (\%) & $26(21)$ & $14(11)$ & \\
\hline $\begin{array}{l}\text { Other (volunteer or unemployed), } \\
\text { No. }(\%)\end{array}$ & $5(4)$ & $7(6)$ & \\
\hline Current smoker, No. (\%) & $23(18)$ & $36(29)$ & .05 \\
\hline Time living together, $y$ & $41(32-47)$ & $42(32-47)$ & .92 \\
\hline $\begin{array}{l}\text { Receiving informal care from } \\
\text { relatives, No. (\%) }\end{array}$ & $15(12)$ & $3(2)$ & .003 \\
\hline Rollator use, No. (\%) & $36(29)$ & $\ldots$ & \\
\hline Cane use, No. (\%) & $27(22)$ & $\cdots$ & \\
\hline Long-term oxygen therapy, No. (\%) & $33(26)$ & $\ldots$ & \\
\hline Exacerbations past $12 \mathrm{mo}$, No. & $2(1-4)$ & $\ldots$ & \\
\hline Charlson comorbidity index, points & $2(1-3)$ & $1(0-2)$ & $<.0001$ \\
\hline Medications in use, No. & $7(5-10)$ & $4(1-6)$ & $<.0001$ \\
\hline BMI, $\mathrm{kg} / \mathrm{m}^{2}$ & $25.3(22.3-29.3)$ & $27.4(24.3-30.4)$ & .001 \\
\hline BMI $<21 \mathrm{~kg} / \mathrm{m}^{2}$, No. (\%) & $22(18)$ & $5(4)$ & .001 \\
\hline BMI $\geq 30 \mathrm{~kg} / \mathrm{m}^{2}$, No. (\%) & $25(20)$ & $36(29)$ & .10 \\
\hline $\mathrm{FEV}_{1}, \%$ predicted & $51(33-65)$ & $105(88-117)$ & $<.0001$ \\
\hline $\mathrm{FEV}_{1} / \mathrm{FVC}, \%$ & $40(31-52)$ & $74(66-77)$ & $<.0001$ \\
\hline $\mathrm{FEV}_{1} / \mathrm{FVC}<70 \%$, No. (\%) & $125(100)$ & $39(32)$ & $<.0001$ \\
\hline GOLD $2 / 3 / 4$, No. (\%) & $67(54) / 39(31) / 19(15)$ & $\ldots$ & \\
\hline GOLD A/B/C/D, No. (\%) & $5(4) / 32(26) / 2(2) / 84(68)$ & $\cdots$ & \\
\hline $\mathrm{FFM}^{\mathrm{a}} \mathrm{kg}$ & $50.7(45.9-55.9)$ & $52.1(47.3-58.3)$ & .11 \\
\hline FFMI, ${ }^{a} \mathrm{~kg} / \mathrm{m}^{2}$ & $18.0(17.2-19.3)$ & $19.1(18.1-20.4)$ & $<.0001$ \\
\hline FFMI $<$ 5th percentile, ${ }^{a}$ No. (\%) & $17(15)$ & $5(4)$ & .007 \\
\hline TUG time, s & $9.9(8.5-11.7)$ & $9.0(7.8-10.2)$ & .005 \\
\hline TUG time $>11 \mathrm{~s}$, No. (\%) & $38(31)$ & $20(16)$ & .007 \\
\hline mMRC, points & $2(2-4)$ & $\ldots$ & \\
\hline CAT, points & $20 \pm 7$ & $\ldots$ & \\
\hline EQ-5D index score, points & $0.78(0.66-0.90)$ & $0.89(0.81-1.00)$ & $<.0001$ \\
\hline CDS, points & $71(66-74)$ & $75(74-75)$ & $<.0001$ \\
\hline $\begin{array}{l}\text { Care dependent (CDS } \leq 68 \text { points), } \\
\quad \text { No. }(\%)\end{array}$ & $42(34)$ & $4(3)$ & $<.0001$ \\
\hline HADS anxiety, points & $5(3-8)$ & $5(2-8)$ & .47 \\
\hline HADS anxiety $\geq 10$ points, No. (\%) & $18(14)$ & $20(16)$ & .73 \\
\hline
\end{tabular}




\begin{tabular}{l|c|c|c}
\hline Characteristics & $\begin{array}{c}\text { Patients With COPD } \\
(n=125)\end{array}$ & $\begin{array}{c}\text { Resident Loved Ones } \\
(n=125)\end{array}$ & $P$ Value \\
\hline HADS depression, points & $5(3-8)$ & $4(2-5)$ & $<.0001$ \\
HADS depression $\geq 10$ points, No. $(\%)$ & $21(17)$ & $5(4)$ & .001 \\
\hline
\end{tabular}

Data expressed as absolute and relative frequency, mean $\pm \mathrm{SD}$, or median (interquartile range). CAT $=\mathrm{COPD}$ assessment test; $C D S=$ Care Dependence Scale; EQ-5D = EuroQol-5 Dimensions; FFM = fat-free mass; FFMI = fat-free mass index; GOLD = Global Initiative for Chronic Obstructive Lung Disease; HADS $=$ Hospital Anxiety and Depression Scale; $\mathrm{mMRC}=$ modified Medical Research Council; TUG $=$ Timed Up \& Go.

${ }^{a} n=114$ for patients with COPD and $n=115$ for resident loved ones.

\section{Exercise Motivation}

Concerning exercise motivation, resident loved ones endorsed more intrinsic regulation than did patients (Table 3). No differences were observed in other exercise motivation constructs.

\section{Physical Activity in Loved Ones}

Comparisons between physically active $(\mathrm{n}=38$ [30\%]) and physically inactive loved ones $(\mathrm{n}=87[70 \%])$ can be found in e-Tables 3 and 4 . Active loved ones were younger, used less medication, had better functional mobility, and showed stronger intrinsic motivation than did inactive loved ones. Tables 4 and 5 present the comparisons between the patients of these two groups. Patients with an active loved one were younger, had a lower BMI, and worse airflow limitation than patients with an inactive loved one (Table 4). After controlling for age, BMI, and degree of airflow limitation, patients with an active loved one were found to spend more time in MVPA than were those with an inactive loved one
(Table 5, e-Fig 2). More time in $\geq 10$-min bouts of MVPA, as well as a higher frequency and a longer duration of these bouts, was also observed in patients with an active loved one (Table 5, e-Fig 3). Sensitivity analyses revealed that these results remained unchanged after removing participants who reported current participation in pulmonary rehabilitation (e-Table 5). Moreover, patients with an active loved one were more often considered physically active than were patients with an inactive loved one ( $29 \%$ vs $10 \%$, respectively; $P=.02$ ) (Table 5). No other differences were observed. Logistic regression showed a higher likelihood of being physically active among patients with an active loved one (OR, 3.14; 95\% CI, 1.20-8.21; $P=.02$ ) even after adjusting for age, BMI, and $\mathrm{FEV}_{1}(\mathrm{OR}, 4.36$; $95 \% \mathrm{CI}$, 1.41-13.30; $P=.01$ ). Daily hourly patterns revealed a similar pattern and a similar intensity of activity in patients with COPD, irrespective of the physical activity level of their loved ones (Fig 2). Conversely, physically active loved ones showed a different pattern, with the

TABLE 2 ] Physical Activity and Sedentary Behavior in Patients With COPD and Their Resident Loved Ones

\begin{tabular}{|c|c|c|c|}
\hline Characteristics & Patients With COPD & Resident Loved Ones & $P$ Value \\
\hline Time in sedentary behavior, $\mathrm{min} / \mathrm{d}$ & $616(566-663)$ & $558(498-606)$ & $<.0001$ \\
\hline Time in light activities, $\mathrm{min} / \mathrm{d}$ & $83(52-118)$ & $121(97-170)$ & $<.0001$ \\
\hline Time in MVPA, $\mathrm{min} / \mathrm{d}$ & $12(2-41)$ & $31(16-52)$ & $<.0001$ \\
\hline $\begin{array}{l}\text { Proportion of daily time in sedentary } \\
\text { behavior, \% }\end{array}$ & $86(79-92)$ & $78(69-84)$ & $<.0001$ \\
\hline Proportion of daily time in light activities, \% & $12(7-16)$ & $17(13-24)$ & $<.0001$ \\
\hline Proportion of daily time in MVPA, \% & $2(0-6)$ & $4(2-7)$ & $<.0001$ \\
\hline Time in $\geq 10-\mathrm{min}$ bouts of MVPA, $\mathrm{min} / \mathrm{d}$ & $0(0-10)$ & $2(0-11)$ & .35 \\
\hline $\begin{array}{l}\text { Frequency of } \geq 10 \text {-min bouts of MVPA, } \\
\text { bouts/d }\end{array}$ & $0(0-1)$ & $0(0-1)$ & .16 \\
\hline $\begin{array}{l}\text { Duration of } \geq 10 \text {-min bouts of MVPA, min/ } \\
\text { bout }\end{array}$ & $14(12-18)$ & $15(12-20)$ & .24 \\
\hline Time in non-weight bearing activities, $\mathrm{min} / \mathrm{d}$ & $510 \pm 94$ & $427 \pm 86$ & $<.0001$ \\
\hline Time in weight-bearing activities, $\mathrm{min} / \mathrm{d}$ & $153 \pm 71$ & $206 \pm 62$ & $<.0001$ \\
\hline Time in dynamic activities, $\mathrm{min} / \mathrm{d}$ & $50(29-81)$ & $80(56-106)$ & $<.0001$ \\
\hline Television-viewing time, $\mathrm{h} / \mathrm{d}$ & $3.5(2.5-5.0)$ & $3.0(2.0-4.5)$ & .09 \\
\hline
\end{tabular}

Data expressed as mean \pm SD or median (interquartile range). MVPA = moderate to vigorous physical activity. 


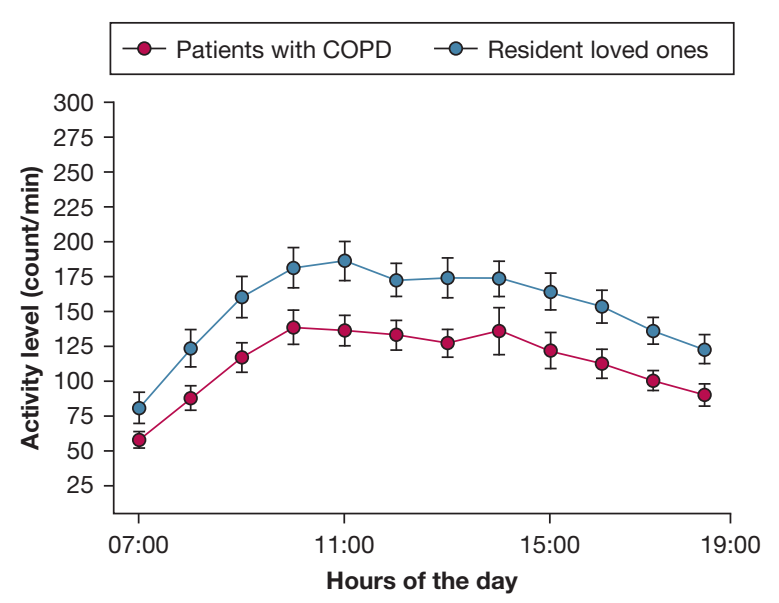

Figure 1 - Hourly patterns of daily physical activity in patients with COPD and their resident loved ones. Data presented as mean (95\% CIs).

peak of intensity during the morning, and performed their activities at a higher intensity compared with physically inactive loved ones (e-Fig 4).

\section{Discussion}

To the best of our knowledge, this is the first study to focus on physical activity, sedentary behavior, and exercise motivation in patients with COPD and their resident loved ones. Despite relatively similar exercise motivation, patients with COPD were found to be less active and more sedentary than their loved ones. Nevertheless, patients with an active loved one were more physically active than those with an inactive loved one.

We observed higher levels of physical activity and a higher likelihood of being physically active among patients with a physically active loved one, and we believe these are the most relevant findings of our study. Resident loved ones can play an important role in helping patients to engage in healthy behaviors. Familybased interventions in other populations have been shown to be useful in achieving healthy behaviors. ${ }^{25,26}$
Family-based interventions target the family setting in which disease management takes place and address the educational, relational, and personal needs of all family members and not only of the patient. ${ }^{27}$ Marques et $\mathrm{al}^{28}$ recently showed that engaging family members of patients with COPD as part of a pulmonary rehabilitation program led to improvements in coping strategies in both patients and family members. With the provision of appropriate information and instructions, resident loved ones can facilitate a more physically active lifestyle in patients with COPD, for example, by encouraging them to go on joint daily walks or to engage more in household activities. Indeed, patients with a chronic pneumopathy previously reported support from family and friends as an enabling factor for participation in physical activity/rehabilitation. ${ }^{29,30}$

We observed more physically active patients among those with a physically active loved one (29\% vs $10 \%)$. However, this means that $71 \%$ of these patients are still physically inactive while their resident loved ones are physically active. Patients in this subgroup are probably the ones who would benefit most from a family-based intervention by encouragements provided by their physically active loved ones. It is important to mention that family-based interventions alone are probably not enough to counteract the physical inactivity observed in patients with COPD, as this is a complex behavior influenced by different factors. A combination of strategies $^{31}$ might be necessary to achieve greater and more sustainable improvements.

Although patients with a physically active loved one were found to be more active than those with a physically inactive loved one, similar levels of sedentariness (high) were observed in both groups. This suggests that having a physically active loved one does not prevent patients from being sedentary and that sedentariness should be reduced in both groups. Epidemiologic data suggest that engaging in MVPA is not enough to fully protect against the detrimental

TABLE 3 ] Exercise Motivation in Patients With COPD and Their Resident Loved Ones

\begin{tabular}{l|c|c|c}
\hline Characteristics & $\begin{array}{c}\text { Patients With COPD } \\
(\mathrm{n}=125)\end{array}$ & $\begin{array}{c}\text { Resident Loved Ones } \\
(\mathrm{n}=125)\end{array}$ & $P$ Value \\
\hline Amotivation, points & $0.25(0.00-1.13)$ & $0.25(0.00-1.25)$ & .90 \\
External regulation, points & $0.63(0.00-1.25)$ & $0.25(0.00-1.50)$ & .15 \\
Introjected regulation, points & $1.00(0.67-2.00)$ & $0.67(0.00-1.92)$ & .07 \\
Identified regulation, points & $3.00(2.06-3.50)$ & $3.00(2.25-3.50)$ & .34 \\
Intrinsic regulation, points & $3.00(2.00-3.75)$ & $3.25(2.50-4.00)$ & .003 \\
\hline \hline
\end{tabular}

Data expressed as median (interquartile range). 
TABLE 4 ] General Characteristics of Patients With COPD With a Physically Active Loved One and Those With a Physically Inactive Loved One

\begin{tabular}{|c|c|c|c|}
\hline Characteristic & $\begin{array}{l}\text { Patients With COPD With a } \\
\text { Physically Active Loved One } \\
\qquad(\mathrm{n}=38)\end{array}$ & $\begin{array}{l}\text { Patients With COPD With a } \\
\text { Physically Inactive Loved One } \\
\qquad(\mathrm{n}=87)\end{array}$ & $P$ Value \\
\hline Male sex, No. (\%) & $22(58)$ & $47(54)$ & .69 \\
\hline Age, y & $64 \pm 8$ & $68 \pm 9$ & .03 \\
\hline Relationship with the loved one & & & .28 \\
\hline Partners (married or not), No. (\%) & $38(100)$ & $84(97)$ & \\
\hline $\begin{array}{l}\text { Son/daughter of the patient, No. } \\
(\%)\end{array}$ & $0(0)$ & $2(2)$ & \\
\hline Friends, No. (\%) & $0(0)$ & $1(1)$ & \\
\hline Working situation & & & .60 \\
\hline Paid job, No. (\%) & $6(16)$ & $7(8)$ & \\
\hline Retired, No. (\%) & $17(45)$ & $46(53)$ & \\
\hline Household work, No. (\%) & $5(13)$ & $13(15)$ & \\
\hline Unable to work, No. (\%) & $10(26)$ & $16(18)$ & \\
\hline $\begin{array}{l}\text { Other (volunteer or unemployed), } \\
\text { No. (\%) }\end{array}$ & $0(0)$ & $5(6)$ & \\
\hline Current smoker, No. (\%) & $8(21)$ & $15(17)$ & .61 \\
\hline Time living together, $y$ & $40(30-45)$ & $43(32-47)$ & .08 \\
\hline $\begin{array}{l}\text { Receiving informal care from } \\
\text { relatives, No. (\%) }\end{array}$ & $6(16)$ & $9(10)$ & .39 \\
\hline Rollator use, No. (\%) & $9(24)$ & $27(31)$ & .40 \\
\hline Cane use, No. (\%) & $6(16)$ & $21(24)$ & .30 \\
\hline Long-term oxygen therapy, No. (\%) & $11(29)$ & $22(25)$ & .67 \\
\hline Exacerbations past $12 \mathrm{mo}$, No. & $2(1-3)$ & $2(0-4)$ & .63 \\
\hline Charlson comorbidity index, points & $2(1-3)$ & $2(1-3)$ & .31 \\
\hline Medications, No. & $6(4-10)$ & $7(5-11)$ & .15 \\
\hline BMI, $\mathrm{kg} / \mathrm{m}^{2}$ & $23.7(21.5-27.4)$ & $25.8(22.8-29.4)$ & .03 \\
\hline BMI $<21 \mathrm{~kg} / \mathrm{m}^{2}$, No. (\%) & $9(24)$ & $13(15)$ & .24 \\
\hline BMI $\geq 30 \mathrm{~kg} / \mathrm{m}^{2}$, No. (\%) & $6(16)$ & $19(22)$ & .44 \\
\hline $\mathrm{FEV}_{1}, \%$ predicted & $40(30-61)$ & $54(36-65)$ & .01 \\
\hline GOLD $2 / 3 / 4$, No. (\%) & $16(42) / 13(34) / 9(24)$ & $51(59) / 26(30) / 10(11)$ & .046 \\
\hline GOLD A/B/C/D, No. (\%) & $2(5) / 9(24) / 1(3) / 26(68)$ & $3(4) / 23(27) / 1(1) / 58(68)$ & .99 \\
\hline $\mathrm{FFM}, \mathrm{kg}^{\mathrm{a}}$ & $49.6(44.8-53.8)$ & $52.0(45.9-56.4)$ & .22 \\
\hline FFMI, $\mathrm{kg} / \mathrm{m}^{2 a}$ & $17.9(16.4-19.0)$ & $18.1(17.5-19.5)$ & .19 \\
\hline FFMI $<$ 5th percentile, No. $(\%)^{a}$ & $4(11)$ & $13(17)$ & .49 \\
\hline TUG time, $\mathrm{s}$ & $9.5(8.3-11.8)$ & $10.0(8.6-11.7)$ & .30 \\
\hline TUG time $>11 \mathrm{~s}$, No. (\%) & $11(29)$ & $27(31)$ & .79 \\
\hline mMRC, points & $3(2-4)$ & $2(1-3)$ & .19 \\
\hline CAT, points & $20 \pm 6$ & $21 \pm 7$ & .35 \\
\hline EQ-5D index score, points & $0.78(0.59-0.93)$ & $0.78(0.69-0.86)$ & .90 \\
\hline CDS, points & $71(64-75)$ & $71(68-74)$ & .83 \\
\hline $\begin{array}{l}\text { Care dependent (CDS } \leq 68 \text { points), } \\
\quad \text { No. }(\%)\end{array}$ & $14(38)$ & $28(32)$ & .54 \\
\hline HADS anxiety, points & $5(3-7)$ & $6(2-8)$ & .65 \\
\hline HADS anxiety $\geq 10$ points, No. (\%) & $5(13)$ & $13(15)$ & .79 \\
\hline
\end{tabular}




\begin{tabular}{l|c|c|c}
\hline & $\begin{array}{c}\text { Patients With COPD With a } \\
\text { Physically Active Loved One } \\
(n=38)\end{array}$ & $\begin{array}{c}\text { Patients With COPD With a } \\
\text { Physically Inactive Loved One } \\
(n=87)\end{array}$ & $\begin{array}{c}P \text { Value } \\
\text { Characteristic }\end{array}$ \\
\hline HADS depression, points & $5(2-8)$ & $5(3-8)$ & .36 \\
HADS depression $\geq 10$ points, No. $(\%)$ & $5(13)$ & $16(18)$ & .47 \\
\hline \hline
\end{tabular}

Data expressed as absolute and relative frequency, mean $\pm \mathrm{SD}$, or median (interquartile range). See Table 1 legend for expansion of abbreviations. ${ }^{a} n=35$ for patients with COPD with a physically active loved one and $n=79$ for patients with COPD with a physically inactive loved one.

consequences of prolonged periods of sedentary behavior. ${ }^{32,33}$ We have previously suggested that a useful strategy to increase MVPA in patients with COPD might be to reduce the time in sedentary behavior by increasing the time in light activities. ${ }^{7,34}$ Reductions in sedentary time by increases in light activities could help pave the way to future increases in MVPA. ${ }^{7,35}$ This strategy could be useful for resident loved ones as well,

TABLE 5 ] Physical Activity, Sedentary Behavior, and Exercise Motivation of Patients With COPD With a Physically Active Loved One and Those With a Physically Inactive Loved One

\begin{tabular}{|c|c|c|c|}
\hline Characteristics & $\begin{array}{l}\text { Patients With COPD With a } \\
\text { Physically Active Loved One } \\
\qquad(\mathrm{n}=38)\end{array}$ & $\begin{array}{l}\text { Patients With COPD With a } \\
\text { Physically Inactive Loved One } \\
\qquad(\mathrm{n}=87)\end{array}$ & $P$ Value \\
\hline $\begin{array}{l}\text { Season of assessment winter/ } \\
\text { spring/summer/autumn, } \\
\text { No. (\%) }\end{array}$ & $8(21) / 5(13) / 5(13) / 20(53)$ & $19(22) / 8(9) / 22(25) / 38(44)$ & .78 \\
\hline Time in sedentary behavior, $\mathrm{min} / \mathrm{d}$ & $600(582-618)$ & $617(606-629)$ & .13 \\
\hline Time in light activities, min/d & $88(75-101)$ & $84(75-92)$ & .60 \\
\hline Time in MVPA, $\min / \mathrm{d}$ & $31(24-38)$ & $18(14-22)$ & .002 \\
\hline $\begin{array}{l}\geq 30 \min \text { of MVPA on } \geq 5 \mathrm{~d} \text {, No. } \\
(\%)\end{array}$ & $11(29)$ & $10(12)$ & .02 \\
\hline $\begin{array}{l}\text { Proportion of daily time in } \\
\text { sedentary behavior, \% }\end{array}$ & $83(81-86)$ & $86(84-88)$ & .10 \\
\hline $\begin{array}{l}\text { Proportion of daily time in light } \\
\text { activities, \% }\end{array}$ & $12(10-14)$ & $12(11-13)$ & .60 \\
\hline Proportion of daily time in MVPA, \% & $4(3-5)$ & $3(2-3)$ & .003 \\
\hline $\begin{array}{l}\text { Time in } \geq 10 \text {-min bouts of MVPA, } \\
\min / \mathrm{d}\end{array}$ & $10(7-14)$ & $5(3-7)$ & .02 \\
\hline $\begin{array}{l}\text { Frequency of } \geq 10 \text {-min bouts of } \\
\text { MVPA, bouts/d }\end{array}$ & $0.6(0.4-0.8)$ & $0.3(0.2-0.4)$ & .004 \\
\hline $\begin{array}{l}\text { Duration of } \geq 10 \text {-min bouts of } \\
\text { MVPA, min/bout }\end{array}$ & $19(16-23)$ & $14(12-17)$ & .03 \\
\hline $\begin{array}{l}\text { Time in non-weight bearing } \\
\text { activities, } \mathrm{min} / \mathrm{d}\end{array}$ & $512(484-540)$ & $509(491-527)$ & .86 \\
\hline $\begin{array}{l}\text { Time in weight-bearing activities, } \\
\min / \mathrm{d}\end{array}$ & $143(121-166)$ & $157(143-172)$ & .31 \\
\hline Time in dynamic activities, $\mathrm{min} / \mathrm{d}$ & $63(53-73)$ & $52(46-59)$ & .08 \\
\hline Television-viewing time, h/d & $4.1(3.4-4.8)$ & $3.8(3.3-4.2)$ & .43 \\
\hline \multicolumn{4}{|l|}{ Exercise motivation, points } \\
\hline Amotivation & $0.70(0.41-1.00)$ & $0.63(0.44-0.82)$ & .70 \\
\hline External regulation & $0.84(0.55-1.14)$ & $0.82(0.63-1.01)$ & .90 \\
\hline Introjected regulation & $1.26(0.94-1.58)$ & $1.26(1.05-1.47)$ & .99 \\
\hline Identified regulation & $2.63(2.31-2.94)$ & $2.71(2.50-2.91)$ & .67 \\
\hline Intrinsic regulation & $2.80(2.46-3.13)$ & $2.72(2.50-2.94)$ & .72 \\
\hline
\end{tabular}

Data expressed as absolute and relative frequency or mean (95\% CI). See Table 2 legend for expansion of abbreviations.

${ }^{\mathrm{a}}$ After controlling for age, BMI, and $\mathrm{FEV}_{1}$. 


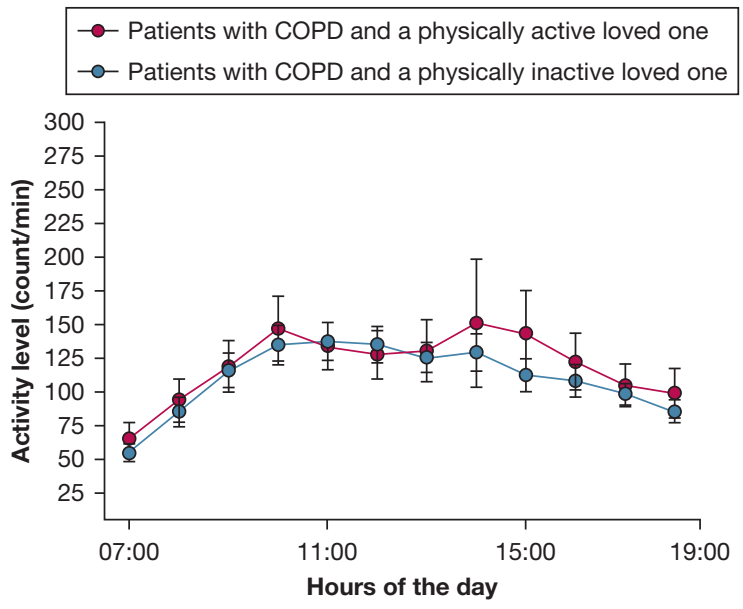

Figure 2 - Hourly patterns of daily physical activity in patients with COPD and a physically active resident loved one and patients with COPD with a physically inactive resident loved one. Data presented as mean $(95 \%$ CIs).

since $70 \%$ of them failed to reach the minimal level to be considered physically active. This amount is higher than that reported previously for European older adults based on data from self-reports $(30 \%-50 \%)^{36}$ but is similar to findings using objectively measured data (about $72 \%)^{37}$

In our study, we also investigated daily activity hourly patterns, which have not been widely explored in COPD. We observed a similar pattern (ie, similar traces) between patients and their loved ones. Nevertheless, loved ones performed their activities at a higher intensity than did patients, as there was no overlap between the 95\% CIs of the traces of the two groups. When we compared hourly patterns between patients with a physically active loved one and those with a physically inactive loved one, a similar flattened pattern was observed in both groups. This suggests more sustained inactivity throughout the day in both groups and could seem to contradict the higher level of MVPA observed in patients with a physically active loved one (Table 5). However, we believe this higher level of MVPA is probably spread throughout the day, which possibly explains why it did not show in the hourly pattern. Moreover, as highlighted previously, daily hourly patterns seem to complement the information provided by other measures of physical activity and sedentary behavior. $^{34}$

Despite presenting with different levels of physical activity and sedentariness, patients with COPD and their loved ones showed relatively similar exercise motivation. Although an association between activity levels and exercise motivation could be hypothesized, a very poor relationship between these outcomes was previously reported. ${ }^{38}$ Intrinsic regulation was the only construct to differ between these groups, with patients with COPD showing less of this type of regulation (Table 3). Intrinsic regulation refers to engaging in exercise for the enjoyment or inherent satisfaction of itself. ${ }^{16}$ We believe patients with COPD showed less of this type of regulation because of the discomfort caused by shortness of breath during exercise, ${ }^{5}$ which prevents them from enjoying this activity. Regardless of the reason, a previous study observed that intrinsic motivation for exercise in COPD can be improved with daily physical activity counseling. ${ }^{39}$

Strengths from the present study include the considerable number of participants (125 patients with COPD and 125 loved ones) with objective measurement of activity levels and simultaneous assessment during a full week. Nevertheless, some limitations are acknowledged. Our sample is composed mainly of patients from secondary care, which may limit extending our findings to primary or tertiary care patients. ${ }^{40}$ Moreover, most patients were in GOLD grade 2 or 3 and GOLD group B or D, and small samples sizes were observed in the remaining groups. These limitations may also compromise the generalizability of our findings, especially when considering that activity levels may differ between GOLD grades ${ }^{41}$ and groups. ${ }^{34}$ Activity monitoring was restricted to the leg, which means that activities of the upper arms were underrepresented. Nevertheless, previous findings suggest that leg activities seem to be more impaired than arm activities in COPD. ${ }^{42}$ Another potential limitation is the use of absolute cut points to define the intensity of activity. Although there are limitations with this approach, the alternative approach (cut points that are relative to the patient's maximal aerobic capacity) is not free of limitations either, as highlighted previously. ${ }^{3}$ Moreover, data on maximal aerobic capacity were not collected in the Home Sweet Home study. Finally, some of our findings need to be interpreted with caution in light of the number of multiple comparison tests performed. ${ }^{43}$ Nonetheless, multiple findings in the same direction rather than a single statistically significant result are suggestive that these are not due to chance alone.

\section{Conclusions}

In summary, patients with COPD are less physically active and more sedentary than their resident loved ones, despite relatively similar exercise motivation. 
Nonetheless, patients with a physically active loved one spend more time in physical activity and have a higher likelihood of being physically active than those with a physically inactive loved one. This suggests that patients' resident loved ones could be used as a way to facilitate a more physically active lifestyle by patients. Future studies are warranted on the efficacy of family-based physical activity counseling in patients with COPD and their resident loved ones.

\section{Acknowledgments}

Author contributions: R. M. is the guarantor of the manuscript. He had full access to all the data in the study, takes responsibility for the integrity of the data and accuracy of the data analysis, and assumes full responsibility for the integrity of the submission as a whole, from inception to published article. R. M., N. N., D. J. A. J., and M. A. S. were involved in the conception, hypothesis delineation, and design of the study. R. M. was responsible for the statistical analysis. R. M. and M. A. S. drafted the first version of the manuscript. N. N., E. H. A. v. d. B., J. M. L. D., M. v. V., G. J. d. V., and J. W. M. M. contributed to the recruitment of participants or the acquisition of data, or both. R. M., J. M. N. E., and K. M. contributed to the management and analysis of physical activity data. All authors revised the article critically for important intellectual content and gave final approval.

Financial/nonfinancial disclosures: The authors have reported to CHEST the following: R. M. is supported by the National Council of Scientific and Technological Development (CNPq), Brazil (246704/ 2012-8). None declared (N. N., D. J. A. J., E. H. A. v. d. B., J. M. L. D., J. M. N. E., K. M., M. v. V., G. J. d. V., J. W. M. M., F. P., E. F. M. W., M. A. S.).

Other contributions: The authors are grateful to Ivy Timmermans (CIRO, Horn, the Netherlands) for input of the data. The authors are grateful to the doctors and nurses of the following collaborating hospitals and their departments of respiratory medicine for their participation in this study: Zuyderland, Heerlen/Kerkrade/Brunssum, the Netherlands; Zuyderland, Sittard-Geleen, the Netherlands; Elkerliek Hospital, Helmond, the Netherlands; and St. Anna Hospital, Geldrop, the Netherlands.

Role of sponsors: The sponsor had no role in the design of the study, the collection and analysis of the data, or the preparation of the manuscript.

Additional information: The e-Appendix, e-Figures, and e-Tables can be found in the Supplemental Materials section of the online article.

\section{References}

1. Annegarn J, Meijer K, Passos VL, et al. Problematic activities of daily life are weakly associated with clinical characteristics in COPD. J Am Med Dir Assoc. 2012;13(3):284-290.
2. Pitta F, Troosters T, Spruit MA, Probst VS, Decramer M, Gosselink R. Characteristics of physical activities in daily life in chronic obstructive pulmonary disease. Am J Respir Crit Care Med. 2005;171(9):972-977.

3. Cavalheri V, Straker L, Gucciardi DF, Gardiner PA, Hill K. Changing physical activity and sedentary behavior in people with COPD. Respirology. 2016;21(3):419-426.

4. Van Remoortel H, Hornikx M, Langer D, et al. Risk factors and comorbidities in the preclinical stages of chronic obstructive pulmonary disease. Am J Respir Crit Care Med. 2014;189(1):30-38.

5. Vestbo J, Hurd SS, Agusti AG, et al. Global strategy for the diagnosis, management, and prevention of chronic obstructive pulmonary disease: GOLD executive summary. Am J Respir Crit Care Med. 2013;187(4):347-365.

6. Vanfleteren LE, Spruit MA, Wouters EF, Franssen FM. Management of chronic obstructive pulmonary disease beyond the lungs. Lancet Respir Med. 2016;4(11): 911-924.

7. Spruit MA, Pitta F, McAuley E, ZuWallack RL, Nici L. Pulmonary rehabilitation and physical activity in patients with chronic obstructive pulmonary disease. Am J Respir Crit Care Med. 2015;192(8):924-933.

8. Burtin C, Langer D, van Remoortel H, et al. Physical activity counselling during pulmonary rehabilitation in patients with COPD: a randomised controlled trial. PLoS One. 2015;10(12):e144989.

9. Vaes AW, Cheung A, Atakhorrami M, et al. Effect of 'activity monitor-based' counseling on physical activity and health-related outcomes in patients with chronic diseases: a systematic review and meta-analysis. Ann Med. 2013;45(5-6): 397-412.

10. King AC. Interventions to promote physical activity by older adults. J Gerontol A Biol Sci Med Sci. 2001;56 Spec No 2: 36-46.

11. Nakken N, Spruit MA, van den Bogaart EH, et al. Health status and morbidities in resident relatives of patients with COPD. J Am Med Dir Assoc. 2016;17(3):276 e271-e278.

12. Nakken N, Janssen DJ, van den Bogaart EH, Vercoulen JH, Wouters EF, Spruit MA. An observational, longitudinal study on the home environment of people with chronic obstructive pulmonary disease: the research protocol of the Home Sweet Home study. BMJ Open. 2014;4(11): e006098.
13. Smid DE, Wilke S, Jones PW, et al. Impact of cardiovascular comorbidities on COPD Assessment Test (CAT) and its responsiveness to pulmonary rehabilitation in patients with moderate to very severe COPD: protocol of the Chance study. BMJ Open. 2015;5(7):e007536.

14. Mesquita R, Janssen DJ, Wouters EF, Schols JM, Pitta F, Spruit MA. Within-day test-retest reliability of the Timed Up \& Go test in patients with advanced chronic organ failure. Arch Phys Med Rehabil. 2013;94(11):2131-2138.

15. Mesquita R, Wilke S, Smid DE, et al. Measurement properties of the Timed Up \& Go test in patients with COPD. Chron Respir Dis. 2016;13(4):344-352.

16. Markland D, Tobin V. A modification to the Behavioural Regulation in Exercise Questionnaire to include an assessment of amotivation. J Sport Exerc Psychol. 2004;26(2):191-196.

17. Dolan P. Modeling valuations for EuroQol health states. Med Care. 1997;35(11): 1095-1108.

18. Jones PW, Harding G, Berry P, Wiklund I, Chen WH, Kline Leidy N. Development and first validation of the COPD assessment test. Eur Respir J. 2009;34(3): 648-654.

19. Dijkstra A, Tiesinga LJ, Goossen WT, Dassen TW. Further psychometric testing of the Dutch Care Dependency Scale on two different patient groups. Int J Nurs Pract. 2002;8(6):305-314.

20. Zigmond AS, Snaith RP. The hospital anxiety and depression scale. Acta Psychiatr Scand. 1983;67(6):361-370.

21. Annegarn J, Spruit MA, Uszko-Lencer NH, et al. Objective physical activity assessment in patients with chronic organ failure: a validation study of a new single-unit activity monitor. Arch Phys Med Rehabil. 2011;92(11):1852-1857.e1851.

22. van der Weegen $S$, Essers $H$, Spreeuwenberg M, et al. Concurrent validity of the MOX activity monitor compared to the ActiGraph GT3X. Telemed J E Health. 2015;21(4):259-266.

23. Watz H, Waschki B, Meyer T, Magnussen H. Physical activity in patients with COPD. Eur Respir J. 2009;33(2): 262-272.

24. Garber CE, Blissmer B, Deschenes MR et al. American College of Sports Medicine position stand. Quantity and quality of exercise for developing and maintaining cardiorespiratory, musculoskeletal, and neuromotor fitness in apparently healthy adults: guidance for prescribing exercise. 
Med Sci Sports Exerc. 2011;43(7): 1334-1359.

25. Viitasalo A, Eloranta AM, Lintu N, et al. The effects of a 2-year individualized and family-based lifestyle intervention on physical activity, sedentary behavior and diet in children. Prev Med. 2016;87:81-88.

26. Hu J, Wallace DC, McCoy TP, Amirehsani KA. A family-based diabetes intervention for Hispanic adults and their family members. Diabetes Educ. 2014;40(1):48-59.

27. Fisher L, Weihs KL. Can addressing family relationships improve outcomes in chronic disease? Report of the National Working Group on Family-Based Interventions in Chronic Disease. J Fam Pract. 2000;49(6):561-566.

28. Marques A, Jacome C, Cruz J, Gabriel R, Brooks D, Figueiredo D. Family-based psychosocial support and education as part of pulmonary rehabilitation in COPD: a randomized controlled trial. Chest. 2015;147(3):662-672.

29. Thorpe O, Kumar S, Johnston K. Barriers to and enablers of physical activity in patients with COPD following a hospital admission: a qualitative study. Int J Chron Obstruct Pulmon Dis. 2014;9:115-128.

30. Mesquita RB, Morano MT, Landim FL, Collares PM, Pinto JM. Social support network and health of elderly individuals with chronic pneumopathies [Article in
Portugese]. Cien Saude Colet. 2012;17(5): 1125-1133.

31. Mantoani LC, Rubio N, McKinstry B, MacNee W, Rabinovich RA. Interventions to modify physical activity in patients with COPD: a systematic review. Eur Respir J. 2016;48(1):69-81.

32. Healy GN, Dunstan DW, Salmon J, Shaw JE, Zimmet PZ, Owen N. Television time and continuous metabolic risk in physically active adults. Med Sci Sports Exerc. 2008;40(4):639-645.

33. Healy GN, Matthews CE, Dunstan DW, Winkler EA, Owen N. Sedentary time and cardio-metabolic biomarkers in US adults: NHANES 2003-06. Eur Heart J. 2011;32(5):590-597.

34. Mesquita R, Spina G, Pitta F, et al Physical activity patterns and clusters in 1001 patients with COPD [published online ahead of print February 24, 2017]. Chron Respir Dis. http://dx.doi.org/ 10.1177/1479972316687207.

35. Sparling PB, Howard BJ, Dunstan DW, Owen N. Recommendations for physical activity in older adults. BMJ. 2015;350:h100.

36. Hallal PC, Andersen LB, Bull FC, et al Global physical activity levels: surveillance progress, pitfalls, and prospects. Lancet. 2012:380(9838):247-257.

37. Lohne-Seiler H, Hansen BH, Kolle E, Anderssen SA. Accelerometer-determined physical activity and self-reported health in a population of older adults (65-85 years): a cross-sectional study. $B M C$ Public Health. 2014;14:284.

38. Altenburg WA, Bossenbroek L, de Greef MH, Kerstjens HA, ten Hacken NH, Wempe JB. Functional and psychological variables both affect daily physical activity in COPD: a structural equations model. Respir Med. 2013;107(11): 1740-1747.

39. Hospes G, Bossenbroek L, Ten Hacken NH, van Hengel P, de Greef MH. Enhancement of daily physical activity increases physical fitness of outclinic patients with COPD: results of an exercise counseling program. Patient Educ Couns. 2009;75(2):274-278.

40. Smid DE, Spruit MA, Houben-Wilke S, et al. Burden of COPD in patients treated in different care settings in the Netherlands. Respir Med. 2016;118: 76-83.

41. Shrikrishna D, Patel M, Tanner RJ, et al. Quadriceps wasting and physical inactivity in patients with COPD. Eur Respir J. 2012;40(5):1115-1122.

42. Meijer K, Annegarn J, Lima Passos V, et al. Characteristics of daily arm activities in patients with COPD. Eur Respir J. 2014;43(6):1631-1641.

43. Perneger TV. What's wrong with Bonferroni adjustments. BMJ. 1998;316(7139):1236-1238. 